\title{
Comparison between the HCV IRES domain IV RNA structure and the Iron Responsive Element Ebenezer Tumban ${ }^{1,2}$, Jenna M Painter ${ }^{2}$ and William B Lott*1,2,3
}

\author{
Address: ${ }^{1}$ Molecular Biology Program, New Mexico State University, Las Cruces, NM 88003-8001, USA, ${ }^{2}$ Department of Chemistry and \\ Biochemistry, New Mexico State University, Las Cruces, NM 88003-8001, USA and 3Institute for Health and Biomedical Innovation, School of Life \\ Sciences, Queensland University of Technology, Brisbane, QLD 4001, Australia \\ Email: Ebenezer Tumban - etumban@hotmail.com; Jenna M Painter - jmp_scholarships2004@yahoo.com; William B Lott* - b.lott@qut.edu.au \\ * Corresponding author
}

Published: 18 February 2009

Journal of Negative Results in BioMedicine 2009, 8:4 doi:10.1 186/1477-575I-8-4

This article is available from: http://www.jnrbm.com/content/8///4

(C) 2009 Tumban et al; licensee BioMed Central Ltd.

This is an Open Access article distributed under the terms of the Creative Commons Attribution License (http://creativecommons.org/licenses/by/2.0), which permits unrestricted use, distribution, and reproduction in any medium, provided the original work is properly cited.
Received: 13 November 2007

Accepted: 18 February 2009

\begin{abstract}
Background: Serum ferritin and hepatic iron concentrations are frequently elevated in patients who are chronically infected with the hepatitis $\mathrm{C}$ virus $(\mathrm{HCV})$, and hepatic iron concentration has been used to predict response to interferon therapy, but these correlations are not well understood. The HCV genome contains an RNA structure resembling an iron responsive element (IRE) in its internal ribosome entry site (IRES) structural domain IV (dIV). An IRE is a stem loop structure used to control the expression of eukaryotic proteins involved in iron homeostasis by either inhibiting ribosomal binding or protecting the mRNA from nuclease degradation. The HCV structure, located within the binding site of the $40 \mathrm{~S}$ ribosomal subunit, might function as an authentic IRE or by an IRE-like mechanism.
\end{abstract}

Results: Electrophoretic mobility shift assays showed that the HCV IRES domain IV structure does not interact with the iron regulatory protein I (IRPI) in vitro. Systematic HCV IRES RNA mutagenesis suggested that IRPI cannot accommodate the shape of the wild type HCV IRES dIV RNA structure.

Conclusion: The HCV IRES dIV RNA structure is not an authentic IRE. The possibility that this RNA structure is responsible for the observed correlations between intracellular iron concentration and HCV infection parameters through an IRE-like mechanism in response to some other cellular signal remains to be tested.

\section{Background}

Hepatitis C virus (HCV) is a positive-sense single-stranded RNA virus that infects about $1 \%$ of the world's population [1]. Fifty percent of acute infections progress to chronic liver infection and can lead to cirrhosis of the liver and hepatocellular carcinoma [2,3]. A correlation between chronic HCV infection and intracellular iron homeostasis has been empirically established, but the mechanism of this relationship is not understood $[4,5]$. Increased intrac- ellular iron concentration has been shown to enhance HCV IRES-dependent translation, and two cellular factors, p85 and p110, bind to both the HCV internal ribosome entry site (IRES) and the iron responsive element (IRE) in an iron-dependent manner [6]. Serum ferritin and hepatic iron concentrations are frequently elevated in chronically infected patients [7], and hepatic iron concentration has been used as a predictor of response to interferon therapy [8]. 
An RNA structural element located at the junction between the open reading frame (ORF) and the $5^{\prime}$ untranslated region (UTR) of the HCV genome bears striking structural and sequential similarities to the iron responsive element (IRE), an RNA structure found in some eukaryotic mRNA that controls gene expression in response to intracellular iron concentration [9]. If this HCV RNA element functions as an authentic IRE, then iron depletion in an HCV infected cell would be expected to specifically inhibit viral protein expression and could potentially decrease subsequent viral replication. A possible relationship between this HCV RNA structure and the IRE was investigated.

HCV belongs to the Hepacivirus genus of the Flaviviridae family [10]. The RNA genome is approximately $9.6 \mathrm{~kb}$ and serves as a template for both translation and replication. The single long ORF is flanked at the 5' and 3 ' ends by highly structured UTRs, which are essential for initiation of translation and replication, respectively [11]. The hepacivirus and pestivirus genera of Flaviviridae initiate translation via virtually identical non-scanning cap-independent mechanisms that utilize an internal ribosome entry site (IRES) to recruit and assemble the ribosome directly at the initiation site [12-15]. The HCV IRES (figure 1) is a complex and highly conserved RNA structure that is located predominantly within $5^{\prime}$ UTR, but is believed to extend into the $5^{\prime}$ proximal region of the ORF [16]. It is canonically divided into four structural domains. Domain I is required for efficient viral replication and is not required for viral translation. Domains II and III are necessary and sufficient to recruit and assemble the ribosome at the start site [13]. The domain IV (dIV) RNA structure, which is not essential for efficient translation [17] and is unique to hepaciviruses, has no known function. The pestivirus IRES contains structural domains that are analogous to HCV IRES domains I-III, but lacks domain IV. The border between the 5' UTR and the ORF of the pestivirus genome is believed to be unstructured.

The authentic HCV initiation codon resides in the terminal loop of the RNA hairpin structure in the HCV IRES dIV. This structure is unlikely to be tolerated in the RNA binding cleft of the ribosome while the initiation codon occupies the ribosomal P site [17-19], and the ribosomal toeprint on the HCV genome at +15 from the start codon is characteristic of a eukaryotic ribosome bound to unstructured mRNA [20]. Consequently, increased stability of the HCV IRES dIV structure predictably decreases the efficiency of HCV IRES-dependent translation [17]. In addition, the HCV IRES dIV structure must presumably melt to allow the $\mathrm{N}$-terminus of the HCV polyprotein to be translated from the codons in the 5 region of the ORF that are involved in the HCV IRES dIV RNA structure. The apparent requirement that the HCV IRES IIV structure unwinds to allow translation initiation suggests that its presumed viral function occurs either before the ribosome has been recruited to the mRNA or after the translating ribosome has exited the start site, which is consistent with a regulatory RNA element.

The IRE is an example of a translation regulatory RNA element that does not otherwise actively participate in the translation initiation mechanism [9]. The interaction between the IRE and its cognate binding partner, an iron regulatory protein (IRP1 or IRP2), either inhibits gene expression by inhibiting $40 \mathrm{~S}$ ribosomal subunit binding or enhances gene expression by protecting the mRNA from nuclease degradation [21], depending on where the IRE is located in the mRNA. To inhibit ribosomal binding, the IRE must reside within the 40S ribosomal subunit binding site near the 5 ' cap structure. The IRE cannot bind to the 40 S ribosomal subunit while it is bound to an IRP, but it has little effect on the translation initiation efficiency when it is not bound by an IRP. The active IRP concentration is controlled by the intracellular iron concentration. IRP1 is an aconitase enzyme conformer that is formed when the intracellular iron concentration is insufficient to form the characteristic aconitase ironsulfur cluster. IRP2 is homologous to IRP1 but does not form the aconitase iron-sulfur cluster [22]. Like the HCV IRES dIV structure, the IRE must melt to allow the mRNA to occupy the ribosomal RNA binding cleft.

The HCV IRES dIV RNA structure shares many of the IRE consensus structural characteristics[23,24], most closely resembling the human erythroidspecific $\delta$-aminolevulinic acid synthase (eALAS) IRE [25] (figure 2, boxed inset). The eALAS IRE stem contains an unpaired $\mathrm{C}$ residue in the $5^{\prime}$ arm (C-bulge) that is separated from the terminal loop by 5 base pairs. The C-bulge is implicated in a sequencespecific binding interaction with the IRP [26]. A prominent feature of the IRE terminal loop is an intraloop C-G base pair, which is required for its interaction with an IRP. The C-G intraloop base pair solvent-exposes the guanine base at the center of the resultant terminal tri-loop, which is also required for sequence-specific high-affinity binding to the IRP [26]. The consensus sequence of the IRE terminal loop consists of six bases, the first five of which are usually CAGUG. The sixth base can be any nucleotide, so long as it cannot base pair with C. The HCV IRES dIV RNA hairpin incorporates similar features, including a C-containing bulge in $5^{\prime}$ arm of the stem that is separated from the terminal loop by five base pairs and the potential to form an intraloop C-G pair. In fact, the HCV IRES dIV stem differs from the consensus C-bulge IRE in only three significant ways (figure 2, boxed inset). It has an extra adenosine residue in the terminal loop, two extra adenosine residues in the $3^{\prime}$ arm of the stem directly across from the unpaired cytosine residue, and an adenosine residue 


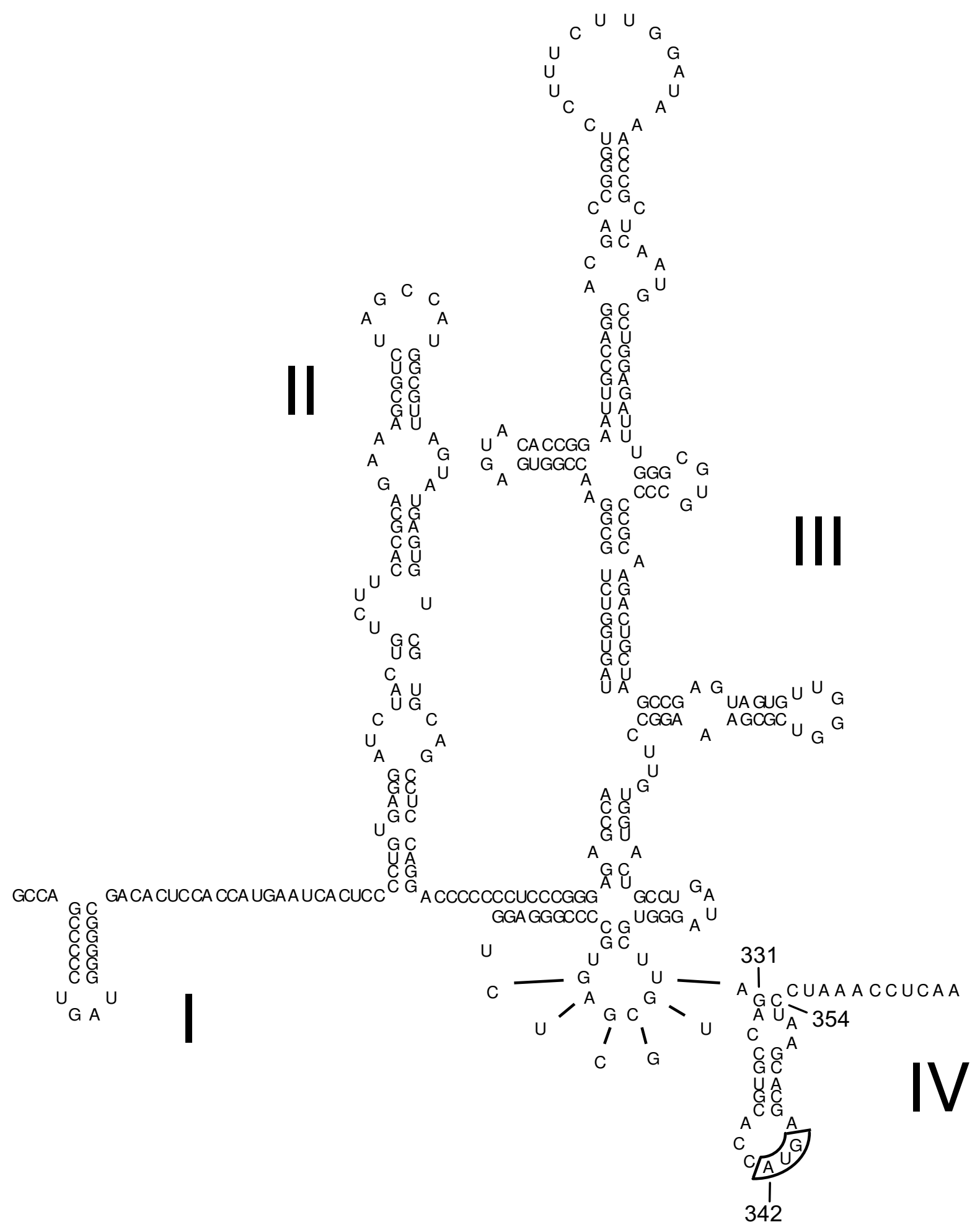

Figure I

The HCV 5'UTR secondary structure. The base pairing convention described by Honda et al [I7] is used to depict the predicted base pairing in the HCV IRES RNA structure for genotype Ib. The structural domains are labelled I-IV. The authentic HCV start codon at HCV nt 342-344 is boxed. The wild type HCV IRES dIV RNA sequence used in this study represents HCV nt $33 \mathrm{I}-354$. 


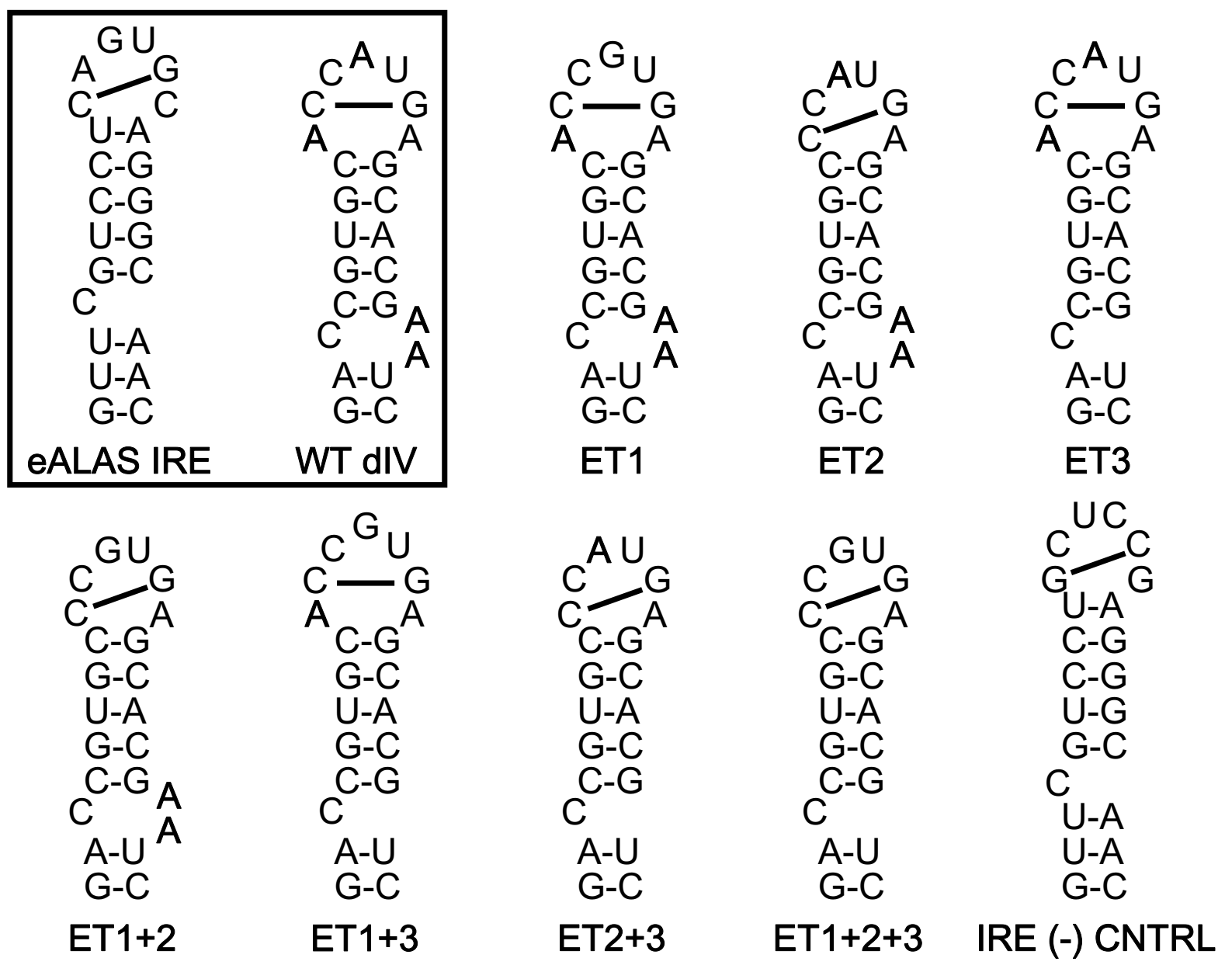

\section{Figure 2}

RNA sequences and secondary structures. Sequences and predicted secondary structures of the RNA panel evaluated in this study. The nucleotides in bold in each construct represent deviations from the consensus C-bulge IRE. Inset: the eALAS IRE and wild type HCV IRES dIV RNA are boxed for comparison.

instead of a guanosine residue at the apex of the putative tri-loop formed by the intraloop C-G base pair. A mutant HCV IRES dIV structure in which all three differences are reconciled would fit the consensus definition of an authentic IRE $[23,24]$ and would be expected to bind to an IRP with wild type affinity.

If HCV were to utilize an IRE-like mechanism to control viral expression, the RNA structure used for this regulation must be positioned within the $40 \mathrm{~S}$ ribosomal subunit binding site. In sharp contrast to normal eukaryotic capdependent translation, the HCV IRES-dependent translation initiation mechanism requires that the $40 \mathrm{~S}$ ribosomal subunit binds directly to the HCV genomic RNA sequence flanking the 5' UTR-ORF boundary to allow the start codon to occupy the ribosomal P site [20]. This mechanism would force at least part of any putative IRE- like RNA element into the ORF. Thus the HCV IRES dIV structure is properly positioned in the HCV mRNA to function as an IRE-like RNA element.

\section{Results}

\section{RNA binding to hIRPI}

Since the HCV IRES dIV structure differs from the consensus IRE at only three characteristics, a mutant RNA panel was constructed to evaluate the relative binding contribution of each characteristic. The panel systematically mutated the wild type HCV IRES dIV structure to a consensus IRE structure (figure 2).

Electrophoretic mobility shift assays (EMSA) were used to detect binding interactions between hIRP1 and the RNA species shown. Although a $100 \mathrm{ng}$ concentration of hIRP1 was reported to bind to the wild type IRE [22], only the 
eALAS IRE and ET1+2+3 bound to hIRP1 at this concentration in our experiments (data not shown). Six of the mutant RNA sequences (ET1+2, ET3, ET2, ET1+3, ET2+3, $\mathrm{ET} 1+2+3)$ and the eALAS IRE detectably bound to hIRP1 at an hIRP1 concentration of $240 \mathrm{ng}$ (figure 3 ). No detectable binding to hIRP1 was observed for the wild type HCV IRES dIV, ET1, ET2, or the negative control IRE. These experiments yielded the following binding trend:

$$
\begin{gathered}
(\mathrm{eALAS} \mathrm{IRE} \approx \mathrm{ET} 1+2+3)>\mathrm{ET} 2+3>\mathrm{ET} 1+3>\mathrm{ET} 3>(\mathrm{ET} 2 \approx \\
\mathrm{ET} 1+2)>(\mathrm{ET} 1 \approx \mathrm{HCV} \text { IRES } \mathrm{dIV} \approx \mathrm{IRE}(-) \text { control })
\end{gathered}
$$

\section{Estimate of the dissociation constant, $K_{d}$}

EMSA was used quantitatively to estimate the dissociation constants $\left(K_{d}\right)$ of the hIRP1-ET2+3 and hIRP1-ET1+2+3 complexes. Unsurprisingly, ET1+2+3, which adheres to the consensus definition of an IRE [23,24], bound to hIRP1 with approximately wild type affinity $\left(K_{d} \sim 50 \mathrm{pM}\right.$, data not shown). ET2 +3 bound to hIRP1 with a $K_{d}=54 \pm$
$13 \mathrm{nM}$ (figure 4B), which is about three orders of magnitude weaker than the consensus IRE.

\section{Discussion}

The HCV IRES has been described as an RNA structural element that regulates viral translation. Strictly speaking, however, the HCV IRES mechanism describes the initiation of translation, not necessarily its regulation. The HCV IRES domains I-III have been well characterized in recent years, and much is known about the roles of these structures in the recruitment and assembly of the eukaryotic ribosome on the HCV RNA genome. The role of domain IV, however, remains enigmatic. It is not required for efficient initiation and is not present in the closely related pestivirus IRES, yet it is conserved across all HCV genotypes. Mutational analysis of this structure demonstrated only a modest relationship between HCV IRES-dependent translational efficiency and structural stability [17]. This observation might simply reflect the effect of RNA structure near the start codon, and does not necessarily imply

\section{RNA-IRP1 Complex}

\section{Free RNA}
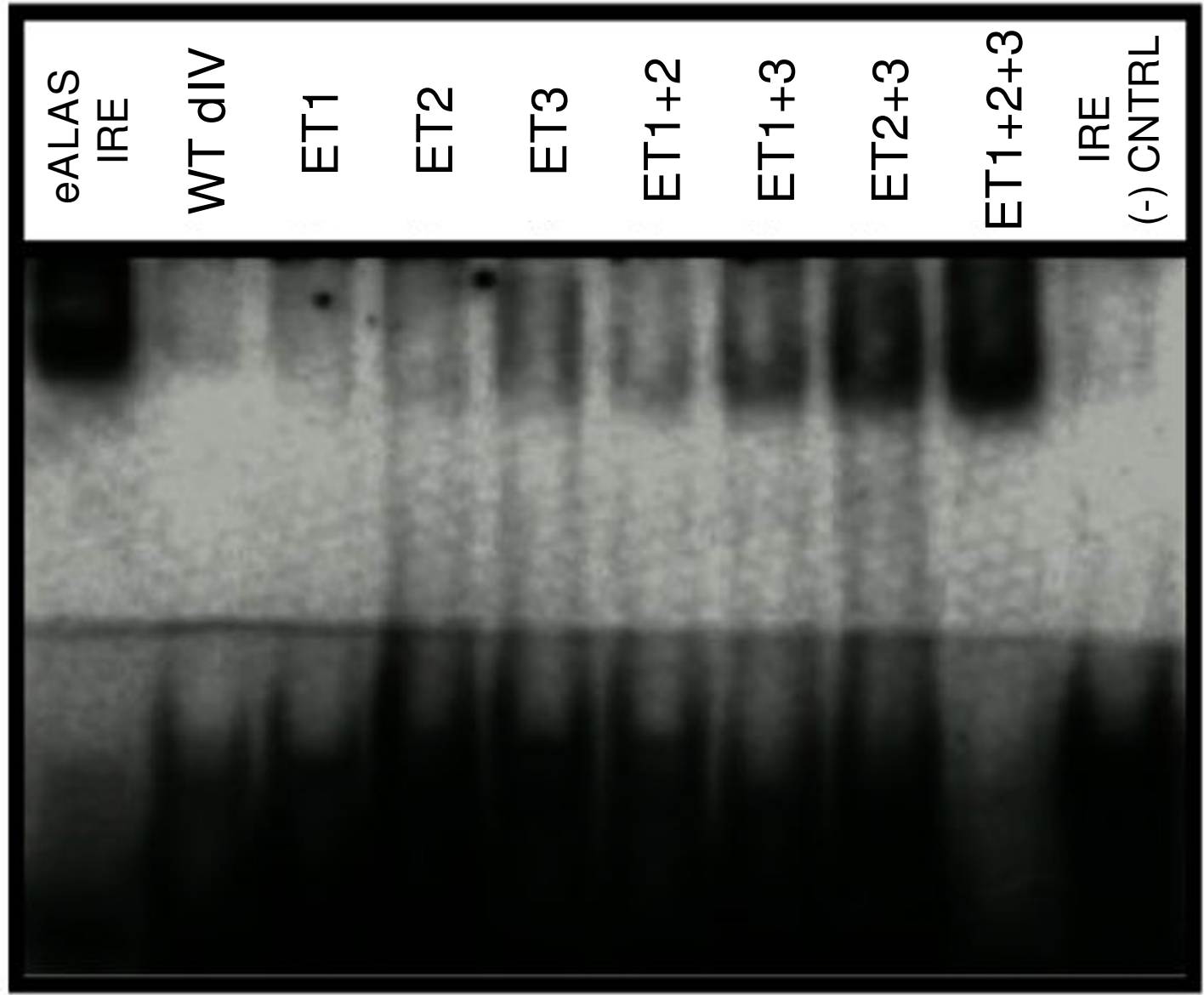

\section{Figure 3}

Relative RNA - hIRP I binding interactions. EMSA showing the relative binding ability of hIRPI to the RNA panel shown in figure 2. 


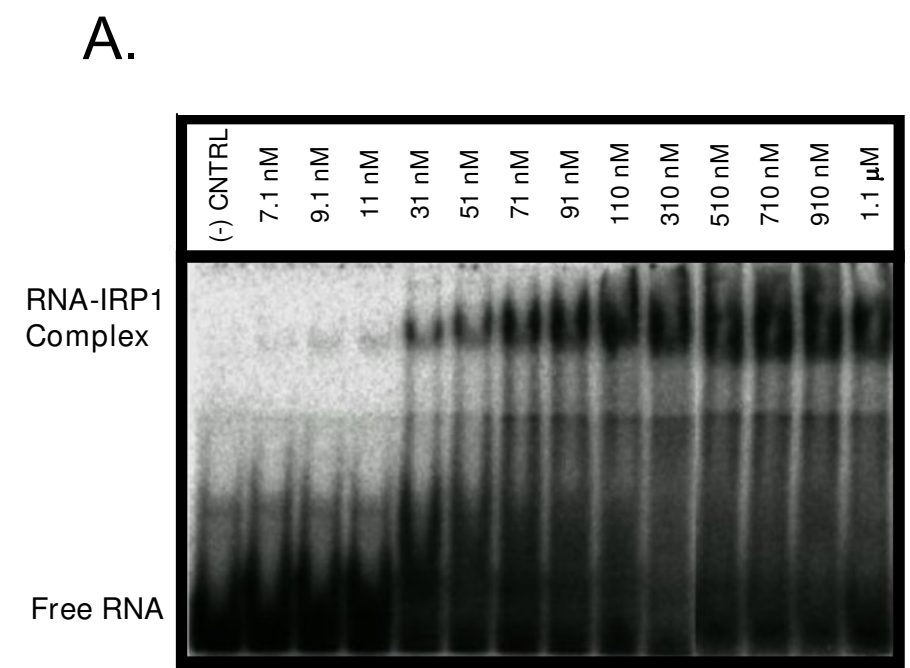

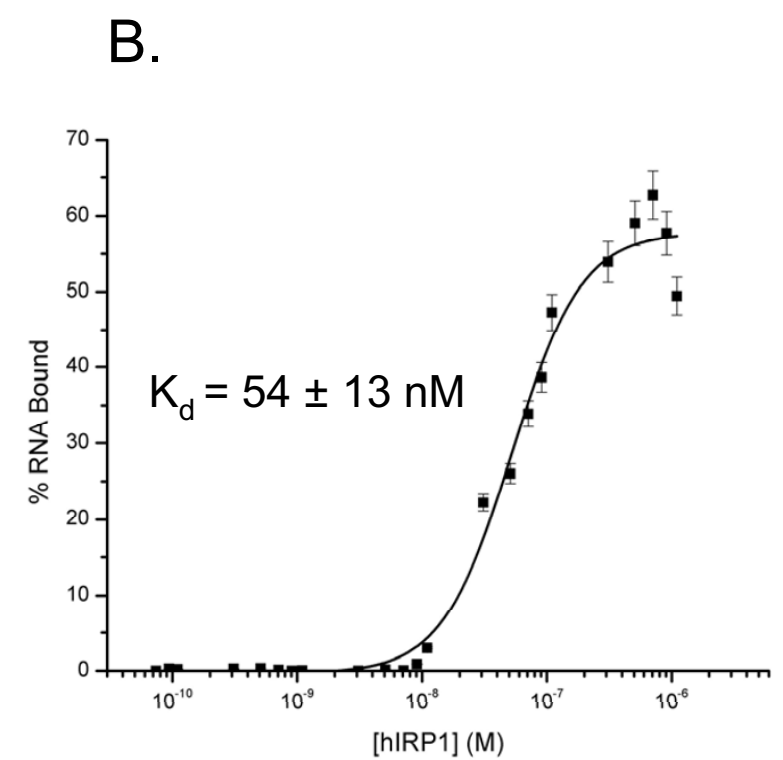

\section{Figure 4}

ET2+3 - hIRPI binding interaction concentration dependence. (A) EMSA showing the hIRPI concentration dependence on binding to ET2+3. Lanes showing hIRPI concentrations of 74 pM-5.I nM were omitted for clarity. (B) Plotted data used to determine the $K_{d}$ for the IRPI-ET2+3 interaction.

a role in translation initiation. These observations are consistent with a regulatory RNA element that modulates translation efficiency in response to an appropriate biological signal but does not otherwise participate directly in the recruitment and assembly of the ribosome. The IREIRP mechanism represents a useful model for this type of interaction.

A cursory comparison of the structure and genomic location of the HCV IRES dIV RNA structure to the C-bulge eALAS IRE is provocative and suggests a correlated similarity of function. The wild type HCV IRES dIV RNA does not measurably bind to hIRP1, however, demonstrating that it is not an authentic IRE. The ET1+2+3 RNA, which adheres to the consensus definition of an IRE, bound to IRP1 with wild type efficiency as expected. Deleting the two A residues in the bulge of the wild type HCV IRES dIV RNA (the ET3 effect) contributed the greatest relative effect on binding affinity, followed by deletion of an A residue in the terminal loop (the ET2 effect), suggesting the importance of the correct three dimensional RNA structure on hIRP1 binding. The $\mathrm{G}$ residue at the apex of the terminal tri-loop and C-bulge residue are conserved in the consensus IRE and are presumably required for sequence-specific interactions between the IRE and recognition motifs on the IRP [9]. These residues are displayed in three dimensions relative to each other by the structural features of the stem and the terminal loop. Altering the IRE structure likely misaligns the recognition nucleotides with their respec- tive recognition motifs on hIRP1. A well-defined and rigid IRE binding pocket would not accept a stem of the wrong shape, regardless of the sequential positions of the recognition nucleotides. The ET2 and ET3 effects are consistent with the reported IRE characteristics required for efficient IRE-IRP interaction [27]. Mutating the A residue of the start codon to a $\mathrm{G}$ residue (the ET1 effect), a sequenceonly mutation, showed the least effect on hIRP1 binding. The ET1 effect was unexpected, since the literature reports that the G residue in the terminal loop is essential [28]. Either purine residue in this position yielded significant IRP1 binding in our hands, with only a slight preference for $\mathrm{G}$ (compare $\mathrm{ET} 2+3$ to ET1+2+3 in figure 3 ).

\section{Conclusion}

The primary conclusion from this work is that the wild type HCV IRES dIV RNA structure is not an authentic IRE, as it does not bind appreciably to the recombinant IRP1 protein. The hypothesis that HCV utilizes this structure to control viral expression by an IRE-like mechanism remains viable, although a putative cellular or viral factor that fulfils the analogous IRP function must be identified to properly evaluate this hypothesis. The p85 and p100 proteins that have been recently shown to bind to both the HCV IRES and the iron responsive element with high affinity [6] could serve this purpose. For now, the role of the highly conserved HCV IRES dIV structure remains unresolved. 


\section{Methods}

Expression and purification of human IRPI

Human IRP1 (hIRP1) fused to glutathione S-transferase (GST) was expressed and purified as previously described [22] with some modifications. The pGEX-2T plasmid (Dr. Lukas Kuhn, ISREC, Epalinges, Switzerland) was transformed into HB101 cells and hIRP1 expression was induced with 0.1 or $0.5 \mathrm{mM}$ IPTG (Sigma-Aldrich, St Louis, MO) overnight at room temperature. Each lysis reaction contained $2 \mathrm{~mL}$ (approximately $0.2 \mathrm{~g}$ ) of cell lysate, $10 \mu \mathrm{L}$ of protease cocktail inhibitor (SigmaAldrich, St Louis, MO) and 15,000 U of lysozyme (Novagen, San Diego, CA). The cells were lysed by sonication in PBS buffer $\left(150 \mathrm{mM} \mathrm{NaCl}, 16 \mathrm{mM} \mathrm{Na} \mathrm{HPO}_{4}, 4 \mathrm{mM}\right.$ $\mathrm{NaH}_{2} \mathrm{PO}_{4}$, pH 7.3) containing $1 \%$ triton-X-100 (SigmaAldrich, St Louis, MO). The cell lysate was then incubated at $4{ }^{\circ} \mathrm{C}$ for 30 minutes and spun at $10,000 \mathrm{rpm}$ for $30 \mathrm{~min}$ utes. hIRP1 was purified on a $50 \%$ glutathione sepharose resin column (Amersham, Piscataway, NJ). The protein was eluted with $50 \mathrm{mM}$ Tris and $10 \mathrm{mM}$ reduced glutathione ( $\mathrm{pH}$ 8.0), concentrated using microcon YM 50 (Millipore, Jaffrey, $\mathrm{NH}$ ) and its concentration, $1.2 \mu \mathrm{g} / \mu \mathrm{L}$, was determined using the Micro Lowry method (SigmaAldrich, St Louis, MO). Purified and unpurified hIRP1 was visualized on an SDS-PAGE and confirmed by Western blot using rabbit anti-rat IRP1 polyclonal antibodies (Alpha Diagnostic, San Antonio, TX).

\section{RNA synthesis}

RNA was synthesized by in vitro transcription from double-stranded DNA oligonucleotides[29,30]. Seven pairs of DNA mutant oligonucleotides corresponding to RNA sequences (ET1, ET2, ET3, ET1+2, ET1+3, ET2+3, and $\mathrm{ET} 1+2+3$ ) were derived from wild type genotype $1 \mathrm{~b} \mathrm{HCV}$ dIV RNA (figure 2). The sequences of the cDNA oligonucleotides representing the wild type HCV dIV RNA (HCV nt 331-354), the seven RNA mutants, a positive control IRE (erythroid $\delta$-aminolevulinate synthase IRE (eALAS IRE)), and a negative control IRE[31], all fused downstream of a T7 bacteriophage promoter were synthesized and purified by PAGE (IDT, Coralville, IA). Complementary oligonucleotides (76 $\mu \mathrm{M}$ each) were annealed in annealing buffer (10 mM MgCl $2,200 \mathrm{mM}$ Tris-HCl, $\mathrm{pH} 8)$ at $95{ }^{\circ} \mathrm{C}$ for 3 minutes, and cooled to room temperature. RNA was transcribed in vitro from $456 \mathrm{nM}$ of each annealed DNA using T7 MAXIscipt (Ambion Inc. Austin, Texas) following the manufacturer's instructions except that $\alpha-{ }^{32} \mathrm{P}$ СТР $(800 \mathrm{Ci} / \mathrm{mmole})$ (MP Biologicals, Irvine, $\mathrm{CA}$ ) and $12.5 \mathrm{U}$ of RNase Inhibitor (Ambion Inc. Austin, Texas) were added. The reactions were incubated at $37^{\circ} \mathrm{C}$ for 1 hour, treated with DNase for 25 minutes, quenched by the addition of $25 \mathrm{nM}$ EDTA (Ambion Inc. Austin, Texas), and the RNA transcripts were purified on a $20 \%$ denaturing PAGE gel.

\section{Electrophoretic mobility shift assays}

EMSAs were used to detect and visualize binding interactions between hIRP1 and the oligoribonucleotides in vitro. Each RNA transcript $\left(0.3 \mathrm{ng}\right.$, approximately $3.0 \times 10^{5}$ cpm) was folded at $75^{\circ} \mathrm{C}$ in $20 \mathrm{mM} \mathrm{MgCl}$ for 2 minutes and was cooled to room temperature. hIRP1 (with GSTtag) was activated with $2 \% \beta$-mercaptoethanol prior to use. Binding reactions consisted of $0.3 \mathrm{ng}$ of each folded RNA transcript and 240 ng of hIRP1 in binding buffer (10 mM HEPES pH 7.6, $2 \mathrm{mM} \mathrm{MgCl}_{2}, 40 \mathrm{mM} \mathrm{KCl}, 5 \%$ glycerol, and $1 \mathrm{mM}$ DTT) to a $20 \mu \mathrm{L}$ total volume. Reaction mixtures were incubated at room temperature for $30 \mathrm{~min}$ utes. Heparin $(0.63 \mu \mathrm{g} / \mu \mathrm{L})$ was then added, and the mixture was incubated at room temperature for 10 additional minutes. RNA-protein complexes were resolved on a discontinuous native polyacrylamide gel (7\% top and $14 \%$ bottom) in $0.5 \times$ TBE buffer to allow both the free and IRP1-bound RNA to be visualized on the same gel. The gel was dried, exposed to a phosphor-imager plate (Molecular Dynamics) overnight. The bands were visualized on a Storm phosphorimager (Molecular Dynamics) and quantified using ImageQuaNT software (Molecular Dynamics).

EMSA was used quantitatively to estimate the dissociation constants $\left(K_{d}\right)$ of the hIRP1-ET2+3 and hIRP1-ET1+2+3 complexes. Activated hIRP1 was serially diluted in binding buffer (10 mM HEPES pH 7.6, $2 \mathrm{mM} \mathrm{MgCl}_{2}, 40 \mathrm{mM}$ $\mathrm{KCl}, 5 \%$ glycerol, and $1 \mathrm{mM} \mathrm{DTT}$ ) to give a final concentration range of $74 \mathrm{pM}$ to $1.1 \mu \mathrm{M}$. Diluted hIRP1 was incubated with $5.2 \mathrm{nM} \alpha^{32}$ P-CTP labeled RNA. Complexed and free RNA species were resolved on a discontinuous native gel (figure 4A), visualized and quantified as previously described. The reported $K_{d}$ is an average of three independent experiments and was calculated by nonlinear curve fit using the Origin program (MicroCal) [32,33] (figure 4B). Calculations assumed that the plateau in the curve represents complete RNA binding and that there was only one hIRP1 binding site on the RNA. To allow for the possibility that the hIRP1-RNA complexes might have dissociated during resolution on the native gel, the complex bands were quantified to include all radioactivity that ran ahead of these complexes with respect to the control lane lacking hIRP1.

\section{Competing interests}

The authors declare that they have no competing interests.

\section{Authors' contributions}

ET synthesized and purified the RNA and hIRP1, carried out the EMSA experiments, and helped draft the manuscript. JMP reproduced and verified the results. WBL conceived of the study, participated in its design and coordination, and drafted the manuscript. All authors read and approved the final manuscript. 


\section{Acknowledgements}

This work was supported by NIH grant number RR-I6480 from the New Mexico IDeA Networks of Biomedical Research Excellence (NM-INBRE) of the National Center for Research Resources, NIH grant number S06 GM 08|36-3I from the Support of Continuous Research Excellence (SCORE) program. We thank Dr. William Severson and Professor Michael Johnson for their helpful discussions, and Dr. Lukas Kuhn (ISREC, Epalinges, Switzerland) for his kind gift of the hIRPI expression construct.

\section{References}

I. Cuthbert JA: Hepatitis C: progress and problems. Clin Microbiol Rev 1994, 7(4):505-532.

2. Saito I, Miyamura T, Ohbayashi A, Harada H, Katayama T, Kikuchi S, Watanabe Y, Koi S, Onji M, Ohta Y, et al.: Hepatitis C virus infection is associated with the development of hepatocellular carcinoma. Proc Natl Acad Sci USA 1990, 87( I 7):6547-6549.

3. Kiyosawa K, Sodeyama T, Tanaka E, Gibo Y, Yoshizawa K, Nakano Y, Furuta S, Akahane $Y$, Nishioka K, Purcell RH, et al.: Interrelationship of blood transfusion, non-A, non-B hepatitis and hepatocellular carcinoma: analysis by detection of antibody to hepatitis C virus. Hepatology 1990, I 2(4 Pt I):67|-675.

4. Di Bisceglie AM, Axiotis CA, Hoofnagle JH, Bacon BR: Measurements of iron status in patients with chronic hepatitis. Gastroenterology 1992, 102(6):2108-2113.

5. Fillebeen C, Muckenthaler M, Andriopoulos B, Bisaillon M, Mounir Z, Hentze MW, Koromilas AE, Pantopoulos K: Expression of the subgenomic hepatitis $\mathrm{C}$ virus replicon alters iron homeostasis in Huh7 cells. J Hepatol 2007, 47(I): I2-22.

6. Cho H, Lee HC, Jang SK, Kim YK: Iron increases translation initiation directed by internal ribosome entry site of hepatitis C virus. Virus Genes 2008, 37(2): $154-160$.

7. Piperno A, D'Alba R, Fargion S, Roffi L, Sampietro M, Parma S, Arosio V, Fare M, Fiorelli G: Liver iron concentration in chronic viral hepatitis: a study of $\mathbf{9 8}$ patients. Eur J Gastroenterol Hepatol 1995, 7(12): 1203-1208.

8. Olynyk JK, Reddy KR, Di Bisceglie AM, Jeffers LJ, Parker TI, Radick JL, Schiff ER, Bacon BR: Hepatic iron concentration as a predictor of response to interferon alfa therapy in chronic hepatitis $C$. Gastroenterology 1995, 108(4): I 104-I I09.

9. Rouault TA: The role of iron regulatory proteins in mammalian iron homeostasis and disease. Nat Chem Biol 2006 2(8):406-4I4.

10. Lindenbach $\mathrm{BD}$, Rice CM: Molecular biology of flaviviruses. Adv Virus Res 2003, 59:23-61.

II. Takamizawa A, Mori C, Fuke I, Manabe S, Murakami S, Fujita J, Onishi $\mathrm{E}$, Andoh T, Yoshida I, Okayama H: Structure and organization of the hepatitis $C$ virus genome isolated from human carriers. J Virol I99I, 65(3): I I05-III3.

12. Poole TL, Wang C, Popp RA, Potgieter LN, Siddiqui A, Collett MS: Pestivirus translation initiation occurs by internal ribosome entry. Virology 1995, 206(I):750-754.

13. Pisarev AV, Shirokikh NE, Hellen CU: Translation initiation by factorindependent binding of eukaryotic ribosomes to internal ribosomal entry sites. C R Biol 2005, 328(7):589-605.

14. Wang C, Sarnow P, Siddiqui A: Translation of human hepatitis $C$ virus RNA in cultured cells is mediated by an internal ribosome-binding mechanism. J Virol 1993, 67(6):3338-3344.

15. Tsukiyama-Kohara K, lizuka $N$, Kohara $M$, Nomoto $A$ : Internal ribosome entry site within hepatitis C virus RNA. J Virol 1992, 66(3): 1476-| 483.

16. Hwang LH, Hsieh CL, Yen A, Chung YL, Chen DS: Involvement of the $5^{\prime}$ proximal coding sequences of hepatitis $C$ virus with internal initiation of viral translation. Biochem Biophys Res Commun 1998, 252(2):455-460.

17. Honda M, Brown EA, Lemon SM: Stability of a stem-loop involving the initiator AUG controls the efficiency of internal initiation of translation on hepatitis C virus RNA. Rna 1996, 2(10):955-968.

18. Rijnbrand R, Bredenbeek PJ, Haasnoot PC, Kieft JS, Spaan WJ, Lemon $S M$ : The influence of downstream protein-coding sequence on internal ribosome entry on hepatitis $C$ virus and other flavivirus RNAs. Rna 200I, 7(4):585-597.

19. Fletcher SR, Ali IK, Kaminski A, Digard P, Jackson RJ: The influence of viral coding sequences on pestivirus IRES activity reveals further parallels with translation initiation in prokaryotes. Rna 2002, 8(12):|1558-|57|.

20. Pestova TV, Shatsky IN, Fletcher SP, Jackson RJ, Hellen CU: A prokaryoticlike mode of cytoplasmic eukaryotic ribosome binding to the initiation codon during internal translation initiation of hepatitis C and classical swine fever virus RNAs. Genes Dev 1998, I 2(I):67-83.

21. Ke Y, Wu J, Leibold EA, Walden WE, Theil EC: Loops and bulge/ loops in iron-responsive element isoforms influence iron regulatory protein binding. Fine-tuning of mRNA regulation? Biol Chem 1998, 273(37):23637-23640.

22. Kaldy P, Menotti E, Moret R, Kuhn LC: Identification of RNAbinding surfaces in iron regulatory protein-I. Embo J 1999, I8(21):6073-6083.

23. Barton HA, Eisenstein RS, Bomford A, Munro HN: Determinants of the interaction between the iron-responsive elementbinding protein and its binding site in rat L-ferritin mRNA. Biol Chem 1990, 265(I 2):7000-7008.

24. Allerson CR, Cazzola M, Rouault TA: Clinical severity and thermodynamic effects of iron-responsive element mutations in hereditary hyperferritinemia-cataract syndrome. J Biol Chem 1999, 274(37):26439-26447.

25. Dandekar T, Stripecke R, Gray NK, Goossen B, Constable A, Johansson $\mathrm{HE}$, Hentze MW: Identification of a novel iron-responsive element in murine and human erythroid delta-aminolevulinic acid synthase mRNA. Embo J 1991, I0(7): 1903-1909.

26. Addess KJ, Basilion JP, Klausner RD, Rouault TA, Pardi A: Structure and dynamics of the iron responsive element RNA: implications for binding of the RNA by iron regulatory binding proteins. J Mol Biol 1997, 274(1):72-83.

27. Jaffrey SR, Haile DJ, Klausner RD, Harford JB: The interaction between the iron-responsive element binding protein and its cognate RNA is highly dependent upon both RNA sequence and structure. Nucleic Acids Res 1993, 2 I(19):4627-4631.

28. Mikulits W, Schranzhofer M, Beug H, Mullner EW: Post-transcriptional control via iron-responsive elements: the impact of aberrations in hereditary disease. Mutat Res 1999 , 437(3):219-230.

29. Milligan JF, Groebe DR, Witherell GW, Uhlenbeck OC: Oligoribonucleotide synthesis using T7 RNA polymerase and synthetic DNA templates. Nucleic Acids Res 1987, I 5(21):8783-8798.

30. Milligan JF, Uhlenbeck OC: Synthesis of small RNAs using T7 RNA polymerase. Methods Enzymol 1989, 180:5I-62.

31. Henderson BR, Menotti E, Kuhn LC: Iron regulatory proteins I and 2 bind distinct sets of RNA target sequences. I Biol Chem 1996, 27 I (9):4900-4908.

32. Haynes SR: RNA-Protein Interaction Protocols. In Methods in Molecular Biology Volume II8. Humana Press; 1999:105-128.

33. Severson W, Partin L, Schmaljohn CS, Jonsson CB: Characterization of the Hantaan nucleocapsid protein-ribonucleic acid interaction. J Biol Chem 1999, 274(47):33732-33739.

Publish with Bio Med Central and every scientist can read your work free of charge

"BioMed Central will be the most significant development for disseminating the results of biomedical research in our lifetime."

Sir Paul Nurse, Cancer Research UK

Your research papers will be:

- available free of charge to the entire biomedical community

- peer reviewed and published immediately upon acceptance

- cited in PubMed and archived on PubMed Central

- yours - you keep the copyright
BioMedcentral 